\title{
Hex open Childhood happiness and violence: a retrospective study of their impacts on adult well-being
}

\author{
Mark A Bellis, ${ }^{1,2}$ Karen Hughes, ${ }^{1}$ Alyson Jones, ${ }^{3}$ Clare Perkins, ${ }^{1,3}$ Philip McHale ${ }^{1}$
}

To cite: Bellis MA, Hughes $\mathrm{K}$, Jones A, et al. Childhood happiness and violence: a retrospective study of their impacts on adult well-being. BMJ Open 2013;3:e003427. doi:10.1136/bmjopen-2013003427

- Prepublication history for this paper is available online. To view these files please visit the journal online (http://dx.doi.org/10.1136/ bmjopen-2013-003427).

Received 17 June 2013 Revised 23 August 2013 Accepted 27 August 2013

\footnotetext{
${ }^{1}$ Centre for Public Health, Liverpool John Moores University, Liverpool, UK ${ }^{2}$ Public Health Wales, Cardiff University, Cardiff, UK

${ }^{3}$ Knowledge and Intelligence Team (North West), Public Health England, Liverpool, UK
}

Correspondence to Professor Mark A Bellis; Mark.Bellis@wales.nhs.uk

\section{ABSTRACT}

Objectives: To examine the hypothesis that adult well-being is related to childhood experiences independent of current adult sociodemographic conditions.

Design: A cross-sectional, stratified, randomised sample survey using self-assessed measures of current well-being and retrospective measures of childhood experiences.

Setting: Households in North West England (September 2012-March 2013).

Participants: The individual with the next birthday in randomly selected households $(n=11500$; compliance $89.6 \%$ of eligible households). Analysis was limited to those aged $\geq 18$ years and answering all pertinent questions ( $n=11$ 157).

Outcomes: The primary outcome was a validated multicomponent measure of mental well-being (MWB). Additional outcomes included self-assessed life satisfaction (LS), life worth and trust in others.

Results: Adult MWB, LS, life worth and trust were all significantly related to childhood violence and happiness. Relationships remained after controlling for sociodemographics. Thus, compared with those with happy, non-violent childhoods, respondents with unhappy, violent childhoods had adjusted ORs (95\% $\mathrm{Cl}$, significance) of 3.10 (2.59 to $3.71, \mathrm{p}<0.001)$ for low MWB, 3.62 (2.99 to 4.38, $p<0.001$ ) for low LS, 4.13 (3.40 to 5.01, $p<0.001$ ) for low life worth and 2.62 (2.20 to $3.11, p<0.001)$ for low trust. The impact of unhappy but non-violent childhoods were smaller but significant $(p<0.001)$. The modelled impact of childhood factors predicted, for instance, that among unemployed white men aged 25-39 years from the most deprived communities, $27 \%$ of those with happy non-violent childhoods would have low MWB rising to $53 \%$ of those with unhappy violent childhoods.

Conclusions: Adult well-being is strongly linked to childhood experiences. The addition of well-being measures to outcomes already associated with adverse childhoods (eg, adolescent antisocial behaviour and risks of adult disease) strengthens the case for investment in interventions to improve childhood experiences. Public health systems are well placed to ensure that policy to improve adult wellbeing exploits the potential for this to be realised through appropriate interventions.

\section{ARTICLE SUMMARY}

Strengths and limitations of this study

- The study utilised a large established survey of adult mental well-being with high levels of compliance, delivered across a diverse population and generating a sample with a wide range of income, employment status and age demographics.

- The incorporation of measures of childhood experiences into an adult well-being survey is largely unexplored and consequently this study required the development of novel measures of childhood adversity and happiness. These measures were subjective and retrospective and require further validation.

- Findings provide additional intelligence linking childhood experiences to adult health and social outcomes. Results should increase the case for investment in research into, and interventions to deliver, improvements in child protection and the quality of childhoods in general.

\section{INTRODUCTION}

Exposure to adverse experiences in childhood can have substantive negative impacts on individuals' physical and mental development, affecting behavioural choices during adolescence and adulthood and ultimately long-term health outcomes. Negative childhood experiences, such as physical or sexual abuse, exposure to domestic violence, family breakdown and bullying in school or community settings, have been associated with poor educational attainment, low employment, substance use, involvement in violence and poor physical and mental health. ${ }^{1-7}$ The psychological and physiological mechanisms linking childhood adversity and poor adult health are increasingly being identified. ${ }^{1}$ 7-9 Thus, exposure to violence and other stressors in childhood can affect brain development and impact, for example, on emotional regulation, cognitive response, attachment, memory and learning. ${ }^{10}$ Without a stable and nurturing childhood environment, children can grow up adapted to stressful 
situations and struggle to function in normal social conditions, for example, having poor attachment, low selfworth and poor social-emotional competencies. ${ }^{11}$ Such effects contribute to relationship difficulties, ${ }^{12}$ poor school performance ${ }^{9}$ and, over the life course, higher risks of health harming behaviours (eg, substance use $^{13}$ ), mental illness (eg, depression, personality disorders, suicide ideation ${ }^{14}$ ) and non-communicable diseases (NCDs; eg, diabetes, circulatory diseases, cancers). ${ }^{12}$

While the evidence base exposing the role of early life experiences on risks of NCDs and mental illness is rapidly expanding, less is known about their impact on adult mental well-being (MWB) and other quality-of-life measures. Studies have found, for example, that physical abuse in childhood can reduce adult psychological well-being and that such relationships are moderated by psychosocial resources including personal control and emotional support. ${ }^{15}{ }^{16}$ However, subjective measures of well-being and quality of life (eg, UK, ${ }^{17}$ Organisation for Economic Co-operation and Development ${ }^{18}$ ) are becoming increasingly important as greater levels of chronic disability and a better understanding of the importance of relative inequity limits the utility of disease and economic-based metrics for health and happiness. ${ }^{19}$ Consequently, governments in a growing range of countries are investing in surveys of subjective well-being (eg, UK, ${ }^{20}$ France, ${ }^{21}$ Bhutan $^{22}$ ) and focusing policy on improving well-being in the general population (eg, England, ${ }^{23}$ Canada, ${ }^{24}$ European Union ${ }^{25}$ ). However, without intelligence on how childhood factors impact adult well-being, policies are likely to focus largely on proximal factors (eg, income, employment, community engagement), potentially missing opportunities to improve adult well-being through childhood intervention.

In this article, we use an established survey of adult MWB ( $n=11$ 157) enhanced with additional measures of self-assessed happiness and exposure to violence in childhood. ${ }^{26}$ We explore the relationships between these childhood measures and current levels of well-being in adulthood, cumulative and protective interactions between childhood measures and their relative contribution to adult well-being compared with established proximal factors (eg, adult residential deprivation). We use four measures of adult well-being, including a validated composite measure of $\mathrm{MWB},{ }^{27} 28$ which is examined at the overall and individual component levels (eg, optimism, usefulness and closeness to others).

\section{METHODS}

The study used data from the second iteration of the North West Mental Well-being Survey, a household survey of residents aged 16 years and over in the North West region of England (population 7056000 in $2011^{29}$ ). The target sample size was 11500 ; calculated to enable the provision of estimates of MWB and life satisfaction (LS) for each of 18 commissioning local health areas and a regionally representative sample. Household selection used a clustered random sample approach with the national Postcode Address File (PAF; a database of all known addresses and postcodes in the UK) employed as the sampling framework and lower super output areas (LSOAs; standard geographical units containing approximately 1500 residents $^{30}$ ) as the primary sampling units. Each LSOA is routinely assigned a measure of deprivation based on the Index of Multiple Deprivation 2010 (IMD), a composite measure comprising 38 indicators of deprivation. ${ }^{31}$ LSOAs were categorised by national IMD quintile and for each local administrative area a random selection of LSOAs was made within deprivation quintiles based on their proportion within the local area. A random selection of households was then made within each selected LSOA for a total of 21694 households, to account for expected ineligibility and non-compliance levels. ${ }^{26}$

Interviews were conducted between September 2012 and March 2013. Trained interviewers attempted four visits to each selected household between the hours of 9:00 and 20:00 on weekdays and 10:00-18:00 on weekends. On contacting the residents, interviewers explained the purpose of the survey and its confidential, anonymous and voluntary nature. Individuals within households were selected on the basis of the person next having a birthday. Attempts were made at only $14737(67.9 \%)$ of selected households before the final sample size of 11500 was reached. Of visited households, 1898 (12.9\%) were ineligible (eg, vacant, nonresidential or demolished properties; household members physically or mentally unable to participate) and $1339(9.1 \%)$ refused to participate. Thus, compliance was $78 \%$ of visited addresses and $89.6 \%$ of eligible households.

Data were collected using hand-held computer-assisted personal interviewing devices ${ }^{32}$ with researchers providing assistance in using devices whenever required (eg, with some elderly respondents). The structured questionnaire included 53 questions covering key demographics (eg, gender, age, ethnicity), relationships, employment, health, well-being and lifestyle behaviours. Employment was categorised as employed (full-time, part-time and self-employed), full-time student, unemployed (including seeking work, not seeking work for reasons of disability), retired and other/domestic (of which $82.6 \%$ were not working for domestic reasons). Ethnicity was recorded using standard UK ethnic group categories ${ }^{33}$ but due to small numbers in most minority groups (only Asian ethnicity exceeded $1 \%$ ) ethnicity was categorised for analysis as white and non-white. As an ecological measure of deprivation, respondents were allocated an IMD 2010 quintile of deprivation based on their LSOA of residence.

Four measures of adult well-being were examined. MWB was measured using the short Warwick-Edinburgh Mental Well-being Scale (SWEMWBS) ${ }^{27}$ an abbreviated alternative to the full version of WEMWBS. SWEMWBS asks individuals to rate their experience during the past 
2 weeks for the following seven items: I've been feeling optimistic about the future; I've been feeling useful; I've been feeling relaxed; I've been dealing with problems well; I've been thinking clearly; I've been feeling close to other people; I've been able to make up my own mind about things. Ratings use a 5-point scale (1, none of the time; 2 , rarely; 3 , some of the time; 4 , often; 5 , all of the time) and an overall MWB score is calculated by summing responses to the seven items. LS was measured using the standard question: 'All things considered, how satisfied are you with your life as a whole nowadays', measured on a scale of 1-10 where one indicates extremely dissatisfied and 10 signifies extremely satisfied. ${ }^{18} 2834$ Two further questions relating to aspects of well-being were analysed: 'Overall, to what extent do you feel the things you do in your life are worthwhile? 20 (henceforth termed life worth; $1=$ not at all worthwhile, $10=$ completely worthwhile); and 'Generally speaking, would you say that most people can be trusted, or that you can't be too careful in dealing with people? '35 (henceforth termed 'trust'; $1=$ can't be too careful, $10=$ most people can be trusted).

Additional questions were added to the standard questionnaire to measure childhood experience. Due to time and space constraints, two single-item questions were used. Self-assessed childhood happiness was measured on a 10-point scale using the question: 'Overall how happy would you say your childhood was' ( $1=$ extremely happy, $10=$ extremely unhappy). Use of a similar singleitem scale elsewhere found that happy childhoods correlated most strongly with factors including social connectedness and personal continuity (eg, parental love, family traditions), and unhappy childhoods with those including poor relationships and stress. ${ }^{36}$ In the absence of a validated single-item question for childhood violence, self-assessed exposure to violence in childhood was measured on a 10-point scale using the question: 'Overall how violent would you say your home life as a child was? This includes violence you may have witnessed at home, not just been directly involved with.' ( $1=$ free from all violence, $10=$ very violent).

For the purposes of analyses, responses to questions on well-being were dichotomised to indicate poor scores as approximately $>1$ SD below the mean (MWB, mean 27.49, SD 5.05, low <22; LS, mean 7.86, SD 1.79, low $<6$; life worth, mean 8.05 , SD 1.81, low $<6$; trust, mean 5.65, SD 2.57, low <3). Childhood measures were similarly dichotomised to indicate a happy/unhappy childhood (mean 2.84, SD 2.22, unhappy $>5$ ) and a non-violent/ violent childhood (mean 1.97, SD 1.97, violent $>4$ ). The seven individual components of SWEMWBS were each dichotomised to indicate poor ratings ( poor=never or rarely in the last 2 weeks, compared with some of the time, often and all of the time responses).

Respondents below the age of 18 were excluded $(n=47)$ from analyses. Individuals missing data on any key variable were also excluded (age $n=90$, ethnicity $\mathrm{n}=24$, LS $\mathrm{n}=33$, life worth $\mathrm{n}=89$, childhood happiness $\mathrm{n}=63$, childhood violence $\mathrm{n}=67$; individuals may have missed more than one data item). The final sample was 11157 (97\% of all those completing the survey). Analyses were undertaken using PASW (Predictive Analytics Software) V.17.0. Statistics utilised $\chi^{2}$ for bivariate explorations of MWB, LS, trust and life worth. Backwards conditional logistic regression was used to examine independent relationships between childhood experiences and measures of adult well-being. Ethical approval for the study was obtained from Liverpool John Moores University.

\section{RESULTS}

The demographic breakdown of the sample is provided in table 1. Each component of SWEMWBS and the overall score were examined for associations with self-reported violent and unhappy childhoods. Poor current measures ('never or rarely' in the last 2 weeks) of optimism, usefulness, relaxation and closeness to others as well as inabilities to cope with problems, think clearly and make up one's own mind were all strongly associated with more violent and unhappy childhoods (table 1). Overall prevalence of low MWB (WEMWBS score <22) was approximately 2.5 times higher in those reporting either unhappy or violent childhoods. Lower levels of self-reported LS, life worth and trust were also associated with violent and unhappy childhoods (table 2). However, these measures and all components of SWEMWBS (table 1) were associated with a range of demographics. Poorer outcomes for all measures were associated with unemployment and increased deprivation (tables 1 and 2). Measures also varied significantly with age with the exception of feeling close to others. Ethnicity had no significant relationship with LS, life worth, trust and most components of MWB; although poor ratings of feeling useful and a low overall SWEMWBS score were significantly associated with white ethnicity. For gender, low optimism, usefulness, closeness to others, LS and life worth were associated with being male but only low relaxation with being female (tables 1 and 2).

Logistic regression analyses were employed to control for confounding demographics and measure independent relationships between childhood violence and happiness and adult MWB (SWEMWBS individual components and overall score), LS, life worth and trust. Figures 1 and 2 present the adjusted ORs of poor outcomes for each adult MWB component with increasing self-rated unhappiness and violence in childhood, respectively. All relationships are significant $(p<0.001)$ with poor MWB components positively related to increasing childhood unhappiness and violence (demographics included in models are as table 1). Poor closeness to others, ability to think clearly and ability to make one's own mind up showed the greatest increases in odds with both increasing unhappiness (figure 1) and violence (figure 2) during childhood. Thus, compared with those with very happy childhoods (1-2 rating on the Likert scale) adjusted odds of poor closeness to 
Table 1 Component and overall mental well-being measures

\begin{tabular}{|c|c|c|c|c|c|c|c|c|c|}
\hline & \multirow[b]{2}{*}{ All } & \multicolumn{7}{|c|}{$\begin{array}{l}* \% \text { of respondents reporting that, in the last } 2 \text { weeks, they have never or rarely } \\
\text { been }\end{array}$} & \multirow[b]{2}{*}{$\begin{array}{l}\% \text { with } \\
\text { below } \\
\text { average } \\
\text { MWB† } \\
\end{array}$} \\
\hline & & $\begin{array}{l}\text { Feeling } \\
\text { optimistic }\end{array}$ & $\begin{array}{l}\text { Feeling } \\
\text { useful }\end{array}$ & $\begin{array}{l}\text { Feeling } \\
\text { relaxed }\end{array}$ & $\begin{array}{l}\text { Dealing } \\
\text { well with } \\
\text { problems }\end{array}$ & $\begin{array}{l}\text { Thinking } \\
\text { clearly }\end{array}$ & $\begin{array}{l}\text { Feeling } \\
\text { close to } \\
\text { others }\end{array}$ & $\begin{array}{l}\text { Able to } \\
\text { make up } \\
\text { own } \\
\text { mind }\end{array}$ & \\
\hline All & & 18.5 & 10.0 & 10.6 & 6.3 & 4.3 & 5.6 & 2.6 & 13.4 \\
\hline \multicolumn{10}{|l|}{ Age group } \\
\hline $18-24$ & 8.7 & 12.2 & 7.5 & 9.8 & 6.5 & 3.4 & 4.7 & 2.8 & 11.1 \\
\hline $25-39$ & 22.0 & 14.7 & 7.1 & 12.2 & 6.8 & 4.5 & 5.9 & 3.0 & 13.7 \\
\hline $40-54$ & 21.4 & 18.4 & 10.0 & 12.9 & 7.1 & 5.5 & 6.4 & 3.2 & 14.3 \\
\hline $55-64$ & 15.6 & 20.7 & 10.6 & 10.7 & 6.7 & 4.2 & 5.0 & 2.3 & 14.2 \\
\hline $65+$ & 32.3 & 21.8 & 12.5 & 8.0 & 5.2 & 3.6 & 5.3 & 2.1 & 12.7 \\
\hline$p$ Value & & $<0.001$ & $<0.001$ & $<0.001$ & 0.024 & 0.003 & 0.158 & 0.049 & 0.064 \\
\hline \multicolumn{10}{|l|}{ Gender } \\
\hline Male & 41.6 & 21.1 & 11.4 & 8.9 & 6.3 & 4.1 & 7.0 & 2.5 & 14.0 \\
\hline Female & 58.4 & 16.7 & 9.0 & 11.7 & 6.4 & 4.1 & 4.6 & 2.6 & 12.9 \\
\hline$p$ Value & & $<0.001$ & $<0.001$ & $<0.001$ & 0.870 & 0.525 & $<0.001$ & 0.758 & 0.095 \\
\hline \multicolumn{10}{|l|}{ Ethnicity } \\
\hline White & 95.8 & 18.6 & 10.2 & 10.6 & 6.3 & 4.3 & 5.7 & 2.6 & 13.5 \\
\hline Non-white & 4.2 & 16.2 & 4.9 & 9.0 & 6.2 & 3.0 & 3.8 & 2.6 & 10.0 \\
\hline p Value & & 0.193 & $<0.001$ & 0.255 & 0.912 & 0.158 & 0.093 & 0.961 & 0.031 \\
\hline \multicolumn{10}{|l|}{ Employment } \\
\hline Employed & 39.0 & 11.4 & 4.2 & 8.2 & 3.6 & 2.3 & 2.7 & 1.4 & 7.8 \\
\hline $\begin{array}{l}\text { Full-time } \\
\text { student }\end{array}$ & 2.4 & 7.2 & 4.9 & 7.2 & 3.8 & 2.3 & 3.0 & 2.6 & 7.9 \\
\hline Unemployed & 12.9 & 32.8 & 24.1 & 20.4 & 17.3 & 11.7 & 15.5 & 7.4 & 31.2 \\
\hline Retired & 36.7 & 21.5 & 12.1 & 8.1 & 5.2 & 3.6 & 5.2 & 2.0 & 13.1 \\
\hline $\begin{array}{l}\text { Other/ } \\
\text { domestic }\end{array}$ & 9.1 & 19.8 & 8.0 & 17.4 & 7.7 & 5.6 & 6.2 & 3.5 & 14.7 \\
\hline $\mathrm{p}$ Value & & $<0.001$ & $<0.001$ & $<0.001$ & $<0.001$ & $<0.001$ & $<0.001$ & $<0.001$ & $<0.001$ \\
\hline \multicolumn{10}{|l|}{ IMD quintile } \\
\hline $\begin{array}{l}\text { (Least } \\
\text { deprived) } 1\end{array}$ & 12.6 & 13.7 & 6.2 & 8.1 & 3.9 & 2.3 & 2.8 & 1.2 & 7.0 \\
\hline 2 & 13.4 & 15.5 & 7.7 & 9.6 & 4.1 & 3.5 & 4.6 & 2.2 & 10.2 \\
\hline 3 & 14.0 & 17.1 & 7.4 & 9.1 & 5.9 & 3.4 & 4.7 & 2.3 & 13.0 \\
\hline 4 & 18.1 & 20.2 & 10.0 & 10.5 & 6.0 & 3.5 & 5.0 & 2.4 & 12.0 \\
\hline $\begin{array}{l}\text { (Most } \\
\text { deprived) } 5\end{array}$ & 42.0 & 20.7 & 12.8 & 12.1 & 8.1 & 5.8 & 7.3 & 3.3 & 17.0 \\
\hline$p$ Value & & $<0.001$ & $<0.001$ & $<0.001$ & $<0.001$ & $<0.001$ & $<0.001$ & $<0.001$ & $<0.001$ \\
\hline \multicolumn{10}{|c|}{ Childhood happiness } \\
\hline Happy & 88.3 & 16.8 & 8.5 & 8.9 & 5.3 & 3.3 & 4.2 & 2.0 & 11.4 \\
\hline Unhappy & 11.7 & 31.4 & 21.5 & 22.9 & 14.2 & 11.5 & 16.0 & 7.3 & 28.0 \\
\hline$p$ Value & & $<0.001$ & $<0.001$ & $<0.001$ & $<0.001$ & $<0.001$ & $<0.001$ & $<0.001$ & $<0.001$ \\
\hline \multicolumn{10}{|c|}{ Childhood violence } \\
\hline Non-violent & 88.8 & 17.3 & 8.7 & 9.2 & 5.2 & 3.3 & 4.3 & 1.9 & 11.3 \\
\hline Violent & 11.2 & 28.4 & 20.5 & 21.3 & 15.2 & 12.0 & 15.6 & 8.1 & 29.9 \\
\hline$p$ Value & & $<0.001$ & $<0.001$ & $<0.001$ & $<0.001$ & $<0.001$ & $<0.001$ & $<0.001$ & $<0.001$ \\
\hline
\end{tabular}

*Variables represent the individual component questions used in the scale. See Methods for full definitions of questions analysed and categorisation of each variable. Statistical analyses used $\chi^{2}$.

tMWB (mental well-being) is measured using Short Warwick-Edinburgh Mental Well-being Scale.

IMD, Index of Multiple Deprivation.

others were 5.88 (95\% CIs 4.28 to 8.08$)$ in those rating their childhood as very unhappy (9-10 rating) and adjusted odds of poor thinking clearly were $5.16(95 \%$ CIs 3.67 to 7.26). Equally adjusted odds of poor closeness and ability to make up one's mind in those with very violent childhoods (ratings $9-10 \mathrm{cv} 1-2$ ) were 5.12
(95\% CIs 3.61 to 7.24$)$ and 4.98 (95\% CIs 3.15 to 7.88$)$ respectively.

There was a significant association between unhappy and violent childhood ( $5.5 \%$ of happy childhoods were violent vs $54.1 \%$ of unhappy childhoods; $\chi^{2}=2737.52$, $\mathrm{p}<0.001)$. Consequently, overall adult SWEMWBS scores 
Table 2 Life satisfaction, life worth and trust in others; their relationships with adult demographics and childhood happiness and violence

\begin{tabular}{|c|c|c|c|}
\hline & \multicolumn{3}{|l|}{ *\% with low } \\
\hline & Life satisfaction & Life worth & Trust \\
\hline All & 10.3 & 9.3 & 15.7 \\
\hline \multicolumn{4}{|l|}{ Age group } \\
\hline $18-24$ & 9.1 & 9.3 & 17.1 \\
\hline 25-39 & 10.5 & 8.6 & 16.7 \\
\hline $40-54$ & 12.7 & 10.6 & 17.0 \\
\hline $55-64$ & 12.0 & 10.3 & 15.4 \\
\hline $65+$ & 8.1 & 8.5 & 14.0 \\
\hline$P$ & $<0.001$ & 0.027 & 0.006 \\
\hline \multicolumn{4}{|l|}{ Gender } \\
\hline Male & 11.5 & 11.0 & 15.5 \\
\hline Female & 9.5 & 8.1 & 15.9 \\
\hline$p$ Value & 0.001 & $<0.001$ & 0.571 \\
\hline \multicolumn{4}{|l|}{ Ethnicity } \\
\hline White & 10.4 & 9.4 & 15.7 \\
\hline Non-white & 8.5 & 7.3 & 17.1 \\
\hline $\mathrm{p}$ Value & 0.196 & 0.118 & 0.401 \\
\hline \multicolumn{4}{|l|}{ Employment } \\
\hline Employed & 5.0 & 4.4 & 12.5 \\
\hline Full-time student & 4.9 & 5.3 & 12.1 \\
\hline Unemployed & 30.9 & 27.2 & 26.6 \\
\hline Retired & 8.3 & 8.5 & 13.7 \\
\hline Other/domestic & 13.4 & 9.3 & 23.1 \\
\hline p Value & $<0.001$ & $<0.001$ & $<0.001$ \\
\hline \multicolumn{4}{|l|}{ IMD quintile } \\
\hline (Least deprived)1 & 6.8 & 6.2 & 10.2 \\
\hline 2 & 8.3 & 7.1 & 10.3 \\
\hline 3 & 8.1 & 7.4 & 12.8 \\
\hline 4 & 9.5 & 8.5 & 14.3 \\
\hline (Most deprived) 5 & 13.4 & 12.0 & 20.7 \\
\hline p Value & $<0.001$ & $<0.001$ & $<0.001$ \\
\hline \multicolumn{4}{|c|}{ Childhood happiness } \\
\hline Happy & 7.8 & 6.9 & 13.8 \\
\hline Unhappy & 29.3 & 27.4 & 29.7 \\
\hline $\mathrm{p}$ Value & $<0.001$ & $<0.001$ & $<0.001$ \\
\hline \multicolumn{4}{|l|}{ Childhood violence } \\
\hline Non-violent & 8.7 & 7.7 & 14.2 \\
\hline Violent & 23.1 & 22.5 & 27.9 \\
\hline p Value & $<0.001$ & $<0.001$ & $<0.001$ \\
\hline
\end{tabular}

and other well-being measures were further investigated by using a metric combining childhood happiness and violence measures into four distinct categories. Thus, individuals' childhoods were classified into the following: happy and non-violent $(n=9307)$; happy but violent $(\mathrm{n}=542)$; unhappy but non-violent $(\mathrm{n}=601)$; unhappy and violent $(n=707)$. Adjusted odds of low overall MWB and low life worth were significantly associated with reports of childhood violence or unhappiness both individually and most strongly when in combination (reference category happy, non-violent childhoods; table 3). Adjusted odds of low LS and trust were highest in those with unhappy and violent childhoods but were also significantly higher in those whose childhoods were unhappy but not violent.

\section{DISCUSSION}

\section{Principal findings}

Consistent with previous studies, ${ }^{26} 37$ we found that unemployment and living in an area of high deprivation had substantive negative impacts on adult well-being (tables 1-3). The highest increases in odds for most measures of low well-being were associated with current unemployment (table 3). However, the impact of an unhappy and violent childhood on well-being largely exceeded increases in odds associated with deprivation (ie, between quintiles 1 and 5). Even after controlling for current employment and deprivation, for example, odds of below average MWB score were three times greater in those with unhappy and violent childhoods than those with happy and non-violent childhoods. Modelling both current demographics and childhood characteristics identifies the potential impact of adverse childhoods on well-being (table 3). For instance, of 100 employed white women aged 40-54 years resident in the most affluent quintile, just 5 would be expected to have low LS given a happy, non-violent childhood; yet this would more than double to 13 if their childhood was unhappy and violent. Similarly, given 100 unemployed white men aged 25-39 years living in the most deprived communities, 27 would be expected to have low MWB following happy, non-violent childhoods; yet if they had unhappy violent childhoods, this would almost double to 53 .

Examining the individual components of MWB scores identified poor ability to feel close to others as being strongly related to violent and unhappy childhoods (figures 1 and 2). This is consistent with previous research findings that retrospective reports of happy childhoods correlate strongly with factors including social connectedness and personal continuity (eg, parental love, family traditions), and an unhappy childhood with those including poor relationships and stress. ${ }^{36}$ Recognition that poor social connectedness is substantively impacted by childhood experiences should inform current strategies to improve population well-being through increasing connectedness. ${ }^{38} 39$

As well as feeling close to others, previous research has identified trust as an important factor in social connectedness and well-being. ${ }^{40} 41$ Findings here suggest that happiness and exposure to violence during childhood may also impact on trusting others in adulthood. Thus, in our study an unhappy and violent childhood had the strongest association with poor levels of trust in adulthood (table 3). Results are also consistent with happy childhoods providing some protective effects against the impact of violence. Thus, individuals with happy childhoods, even when violent, were not significantly more likely to report low trust in others or low LS. However, a happy childhood does not appear to be 
Figure 1 Relationship between changes in childhood unhappiness and self-reported components of poor adult mental well-being (adjusted ORs). Component measures of mental well-being are taken from validated Short

Warwick-Edinburgh Mental Wellbeing Scale (see Methods). Adjusted ORs were calculated using logistic regression analysis. Additional independent variables included in the logistic regression were age, gender, employment, deprivation and ethnicity (see table 1 for categorisation). All relationships are significant $(p<0.001)$ with poor mental well-being components positively related to increasing childhood unhappiness. Ref, reference category used in logistic regression.

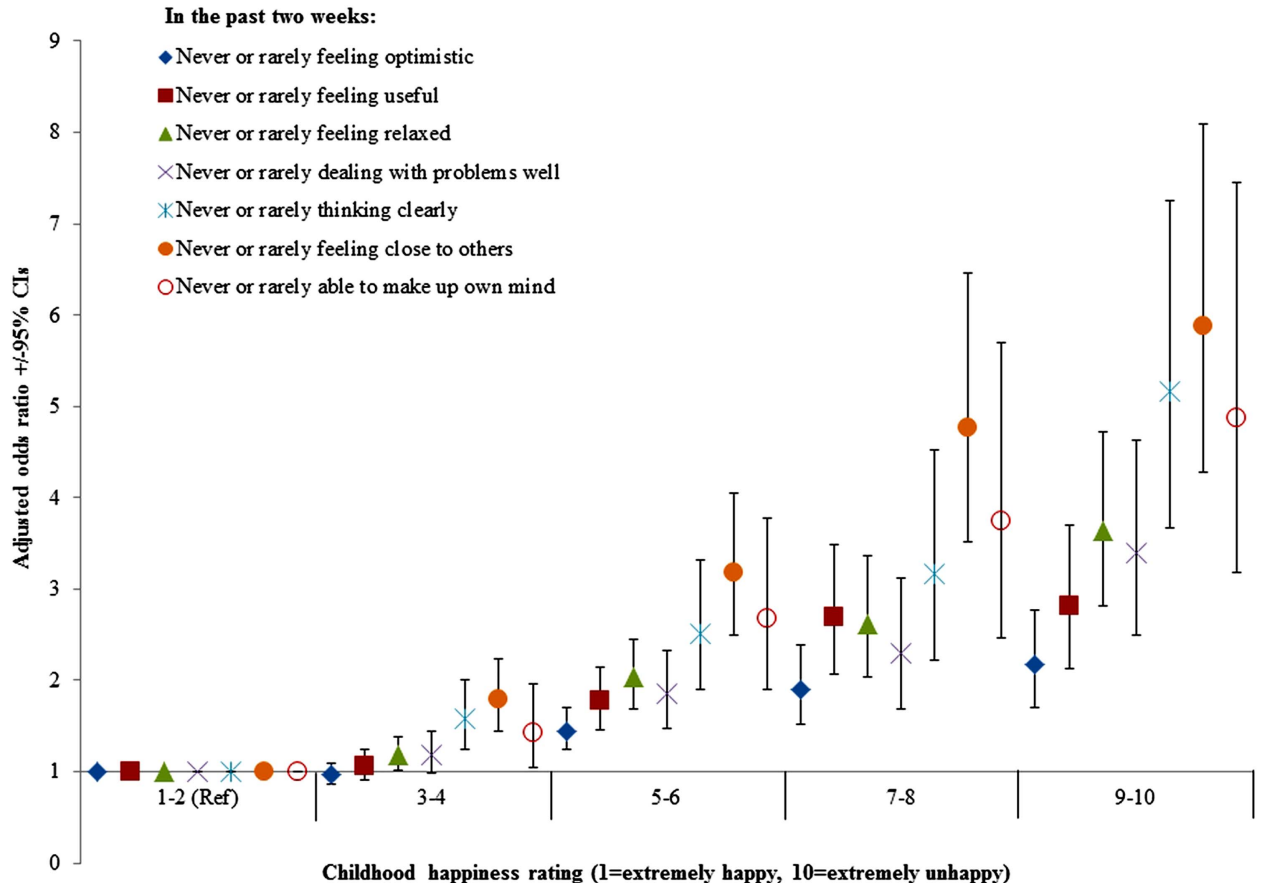

Childhood happiness rating ( $1=$ extremely happy, $10=$ extremely unhappy) protective against the impacts of violence on MWB and life worth (table 3). Equally, unhappy childhoods, even in the absence of violence, were associated with all measures of low well-being (table 3). While considerable policy is concerned with the protection of children from violence, ${ }^{42} 43$ the importance of a happy childhood (and

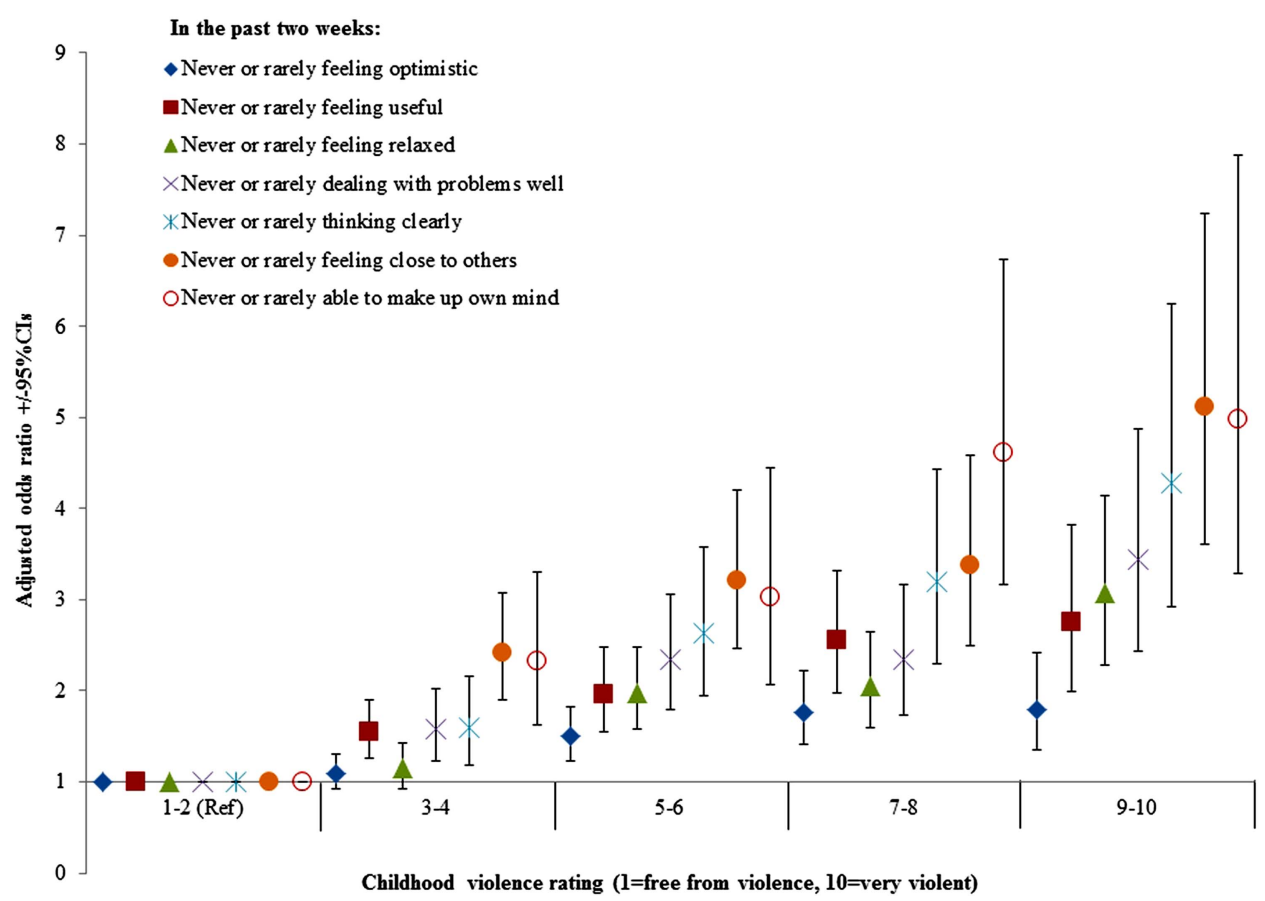

Figure 2 Relationship between changes in childhood violence and self-reported components of poor adult mental well-being (adjusted ORs). Component measures of mental well-being are taken from validated Short Warwick-Edinburgh Mental Wellbeing Scale (see Methods). Adjusted ORs were calculated using logistic regression analysis. Additional independent variables included in the logistic regression were age, gender, employment, deprivation and ethnicity (see table 1 for categorisation). All relationships are significant $(p<0.001)$ with poor mental well-being components positively related to increasing childhood violence. Ref, reference category used in logistic regression. 
Table 3 Changes in adjusted odds of low-reported adult life satisfaction, life worth, trust in others and mental well-being with childhood happiness, violence and current demographic factors

\begin{tabular}{|c|c|c|c|c|c|c|c|c|c|c|c|c|}
\hline & \multicolumn{12}{|l|}{${ }^{*}$ Low } \\
\hline & \multicolumn{2}{|c|}{ Life satisfaction } & \multicolumn{3}{|c|}{ Life worth } & \multicolumn{3}{|c|}{ Trust } & \multicolumn{4}{|c|}{ †Mental well-being } \\
\hline & AOR & $95 \% \mathrm{Cls}$ & $\mathrm{p}$ Value & AOR & $95 \% \mathrm{Cls}$ & $\mathrm{p}$ Value & AOR & $95 \% \mathrm{Cls}$ & p Value & AOR & $95 \% \mathrm{Cls}$ & $p$ Value \\
\hline \multicolumn{13}{|l|}{ Age } \\
\hline $18-24$ (Ref) & & & 0.002 & & & Ns & & & Ns & & & 0.023 \\
\hline $25-39$ & 1.223 & 0.923 to 1.621 & 0.161 & & & & & & & 1.373 & 1.064 to 1.770 & 0.015 \\
\hline $40-54$ & 1.598 & 1.207 to 2.115 & 0.001 & & & & & & & 1.489 & 1.152 to 1.924 & 0.002 \\
\hline $55-64$ & 1.471 & 1.083 to 1.997 & 0.013 & & & & & & & 1.304 & 0.983 to 1.730 & 0.065 \\
\hline $65+$ & 1.172 & 0.796 to 1.725 & 0.422 & & & & & & & 1.130 & 0.800 to 1.597 & 0.487 \\
\hline \multicolumn{13}{|c|}{ ㄱ. } \\
\hline \multicolumn{13}{|l|}{ Female (Ref) } \\
\hline Male & 1.152 & 1.006 to 1.320 & 0.041 & 1.266 & 1.101 to 1.456 & 0.001 & & & Ns & & & Ns \\
\hline \multicolumn{13}{|l|}{ Ethnicity } \\
\hline \multicolumn{13}{|l|}{ White (Ref) } \\
\hline Non-white & 0.707 & 0.497 to 1.006 & 0.054 & & & Ns & & & Ns & 0.658 & 0.477 to 0.907 & 0.011 \\
\hline \multicolumn{13}{|l|}{ Employment } \\
\hline Employed (Ref) & & & $<0.001$ & & & $<0.001$ & & & $<0.001$ & & & $<0.001$ \\
\hline Full-time student & 1.329 & 0.725 to 2.436 & 0.358 & 1.222 & 0.697 to 2.143 & 0.484 & 0.953 & 0.649 to 1.398 & 0.804 & 1.326 & 0.810 to 2.169 & 0.262 \\
\hline Unemployed & 6.186 & 5.131 to 7.458 & $<0.001$ & 5.856 & 4.830 to 7.101 & $<0.001$ & 1.840 & 1.575 to 2.150 & $<0.001$ & 4.049 & 3.428 to 4.782 & $<0.001$ \\
\hline Retired & 1.946 & 1.434 to 2.639 & $<0.001$ & 1.997 & 1.662 to 2.398 & $<0.001$ & 1.138 & 1.001 to 1.293 & 0.047 & 2.121 & 1.627 to 2.766 & $<0.001$ \\
\hline Other/domestic & 2.753 & 2.164 to 3.501 & $<0.001$ & 1.993 & 1.526 to 2.604 & $<0.001$ & 1.768 & 1.483 to 2.108 & $<0.001$ & 1.787 & 1.443 to 2.213 & $<0.001$ \\
\hline \multicolumn{13}{|l|}{ Deprivation quintile } \\
\hline (Least deprived; Ref) 1 & & & 0.006 & & & Ns & & & $<0.001$ & & & $<0.001$ \\
\hline 2 & 0.978 & 0.729 to 1.313 & 0.883 & & & & 0.982 & 0.771 to 1.251 & 0.886 & 1.439 & 1.100 to 1.884 & 0.008 \\
\hline 3 & 1.060 & 0.796 to 1.411 & 0.690 & & & & 1.231 & 0.978 to 1.550 & 0.076 & 1.842 & 1.424 to 2.383 & $<0.001$ \\
\hline 4 & 1.201 & 0.921 to 1.566 & 0.176 & & & & 1.365 & 1.101 to 1.693 & 0.005 & 1.614 & 1.257 to 2.073 & $<0.001$ \\
\hline (Most deprived) 5 & 1.360 & 1.072 to 1.725 & 0.011 & & & & 1.876 & 1.549 to 2.271 & $<0.001$ & 2.035 & 1.623 to 2.552 & $<0.001$ \\
\hline \multicolumn{13}{|l|}{ Childhood } \\
\hline Happy non-violent (Ref) & & & $<0.001$ & & & $<0.001$ & & & $<0.001$ & & & $<0.001$ \\
\hline Happy violent & 1.267 & 0.950 to 1.689 & 0.107 & 1.816 & 1.381 to 2.387 & $<0.001$ & 1.235 & 0.981 to 1.554 & 0.072 & 2.245 & 1.807 to 2.789 & $<0.001$ \\
\hline Unhappy non-violent & 3.429 & 2.780 to 4.229 & $<0.001$ & 3.786 & 3.061 to 4.684 & $<0.001$ & 1.716 & 1.401 to 2.102 & $<0.001$ & 1.701 & 1.367 to 2.117 & $<0.001$ \\
\hline Unhappy violent & 3.616 & 2.988 to 4.376 & $<0.001$ & 4.127 & 3.399 to 5.011 & $<0.001$ & 2.619 & 2.203 to 3.114 & $<0.001$ & 3.100 & 2.590 to 3.710 & $<0.001$ \\
\hline
\end{tabular}

${ }^{*}$ See Methods for full definitions of questions analysed and categorisation of each variable. Analyses used backward conditional logistic regression.

†Mental well-being is measured using the Short Warwick-Edinburgh Mental Well-being Scale.

AOR, adjusted OR; Ns, not significant; Ref, reference category. 
not just one free of violence) for long-term well-being has received less attention. Furthermore, here an unhappy or violent childhood was also related to selfperceived cognitive deficits; that is, ability to make up one's mind and to think clearly (figures 1 and 2). The potential long-term impact of the quality of childhood on well-being, social cohesion and cognitive abilities should be included in arguments for investment in child health, educational and parental support services.

\section{Strengths}

Recently, a robust evidence base has emerged for associations between childhood adversity and poor health outcomes in later life. ${ }^{12}{ }^{4}$ However, there is a dearth of studies describing the impact of childhood adversity on adult well-being. This study provides such data using a large randomly selected population surveyed anonymously and at relatively high levels of survey uptake. While the population was specific to the North West of England, it included individuals across a broad age, employment and deprivation spectrum. The study used four measures of adult well-being, including a validated composite scale of MWB that enabled both overall MWB and individual components of this scale to be examined. Methods for measuring well-being and childhood factors were consistent with previous studies as were associations identified between demographics and both MWB and LS.

\section{Limitations}

Our measures of both current MWB and LS and childhood experience were self-reported and are inevitably open to issues of subjectivity in self-assessment. As with any retrospective surveys we cannot exclude recall bias of childhood experiences. ${ }^{44}$ For example, here individuals who have current low MWB and LS may have been more inclined to report poor-quality childhood measures regardless of actual experiences. ${ }^{45}$ While compliance was high for a door-to-door survey, 9.1\% of individuals approached refused to participate. This survey did not record reasons for refusal, and therefore it is not possible to identify whether childhood experiences, LS and MWB affected refusal. However, refusal typically preceded researchers explaining the nature of the survey and time constraints rather than topic may have resulted in nonparticipation in many cases. As an initial introduction of childhood factors into an adult well-being survey only a limited set of questions on childhood was possible. Our definition of violence in childhood included both violence in which respondents were directly involved and violence witnessed within the home. Ultimately, however, a wider range of validated questions is required. Such sets of standardised questions (eg, the Adverse Childhood Experience tool, ACE) ${ }^{46}$ are becoming increasingly available and should be included in future well-being surveys to better understand links among ACEs, childhood happiness and adult well-being. Finally, our dependent variables (LS and MWB) and key independent variables (unhappy and violent childhoods) were dichotomised. While such practice can result in the loss on information, our analysis was primarily concerned with identifying relationships between poor LS and MWB in adults and lower quality childhoods. Our categorisation process was not arbitrary but used a consistent measure of greater than one SD from the sample mean. ${ }^{47}$

\section{Policy and research implications}

Population level interventions frequently employ advice to the public on behaviour changes necessary to improve well-being. ${ }^{38}$ However, the causes of low adult well-being (eg, poor connectedness) may relate to adverse early life experiences and be stubborn to change once established. Consequently, findings here support health and economic arguments for greater investment in early life interventions to create safe and enjoyable childhoods. Child protection measures (eg, safe-guarding) are an important element in the prevention of child abuse in public and private settings. ${ }^{48}$ More widely, parental support, parent training programmes and early child education ${ }^{49-52}$ can improve parenting skills, increase bonding between parents and children, and reduce child maltreatment. Such interventions can also impact beneficially on school performance and adolescent behavioural outcomes. ${ }^{53}{ }^{54}$ However, their impact on the longer term LS and MWB of children is currently unstudied and the evidence base for their effectiveness, in general, is largely limited to the USA. More broadly, an absence of studies on the factors contributes to a happy childhood needs to be addressed; especially given suggestions here that its absence may have long-term consequences for well-being and its presence offers an element of protection from the impact of childhood violence. Furthermore, this study and others $^{6} 2655$ have identified strong associations between low well-being and both poverty and unemployment (tables 1 and 2). Consequently, how low well-being in parents impacts on childhood happiness and violence and how it may contribute to a life cycle of poor wellbeing needs further study.

\section{CONCLUSIONS}

For health promotion purposes, pathways to improved well-being have been distilled into five activities; connecting with people, being active, noticing of your environment, continued learning and giving to others (known as the five ways to well-being). ${ }^{38}$ While associations among these behaviours and well-being are well established, the efficacy of interventions to change such behaviours and their subsequent impact on well-being are not. Results here suggest that, like health-harming behaviours in adolescence, poor adult well-being is, in part, rooted in childhood experiences. In fact, poor levels of optimism, closeness to others and ability to think clearly may form part of the mechanism by which poor childhoods create an inclination towards health-harming 
behaviours (eg, substance use, poor diet and sexual risktaking) in later life. Consequently, intervention in childhood may not only improve LS, social connectedness, feelings of life worth and overall well-being in adults but also reduce health-harming behaviour in adolescence and ill health in later life. However, ensuring safe and happy childhoods requires multiagency approaches. As well as parenting and early developmental support, criminal justice and social services must ensure effective child protection and domestic violence interventions are in place while schools need both antibullying and engagement policies for marginalised groups. Public health systems are well placed to develop such integrated approaches to childhood and ensure that the case for investment in them reflects their long-term benefits to education, criminal justice, employment and health.

Acknowledgements We would like to thank the members of the North West Mental Wellbeing Survey Steering Group for their valuable support, advice and direction on this work. We would also like to thank Nicola Leckenby, Jennifer Mason, Mark O'Keefe, Jude Stansfield and Tom Hennell for their contributions to the development and delivery of the survey. We also recognise the contributions of the local authorities and primary care trusts who commissioned the mental well-being survey and all those individuals who gave up their time to participate.

Contributors MAB directed the study, analysed the data and wrote the article. $\mathrm{KH}$ analysed data and cowrote the article. AJ co-ordinated the study, analysed data and contributed to the article. CP oversaw the study and edited the article. PM contributed to data analysis and editing of the article.

Funding This work was supported by funding from former primary care trusts in the North West of England.

Competing interests None.

Ethics approval Liverpool John Moores University Research Ethics Committee.

Provenance and peer review Not commissioned; externally peer reviewed.

Data sharing statement Access to the dataset for research purposes will be made available through an open access web resource. Those requiring access to the data before it is available online should contact the corresponding author.

Open Access This is an Open Access article distributed in accordance with the Creative Commons Attribution Non Commercial (CC BY-NC 3.0) license, which permits others to distribute, remix, adapt, build upon this work noncommercially, and license their derivative works on different terms, provided the original work is properly cited and the use is non-commercial. See: http:// creativecommons.org/licenses/by-nc/3.0/

\section{REFERENCES}

1. Anda RF, Felitti VJ, Bremner JD, et al. The enduring effects of abuse and related adverse experiences in childhood. A convergence of evidence from neurobiology and epidemiology. Eur Arch Psychiatry Clin Neurosci 2006;256:174-86.

2. Felitti VJ, Anda RF, Nordenburg D, et al. Relationship of childhood abuse and household dysfunction to many of the leading causes of death in adults: the adverse childhood experiences (ACE) study. Am J Prev Med 1998;14:245-58.

3. Finkelhor D, Shattuck A, Turner $\mathrm{H}$, et al. Improving the Adverse Childhood Experiences Study Scale. JAMA Pediatr 2013;167:70-5.

4. Bellis MA, Lowey $\mathrm{H}$, Leckenby $\mathrm{N}$, et al. Adverse childhood experiences: retrospective study to determine their impact on adult health behaviours and health outcomes in a UK population. J Public Health 2013. doi: 10.1093/pubmed/fdt038

5. Steele F, Sigle-Rushton W, Kravdal O. Consequences of family disruption on children's education outcomes in Norway. Demography 2009;46:553-74.
6. Currie J, Widom CP. Long-term consequences of child abuse and neglect on adult economic well-being. Child Maltreat 2010;15:111-20.

7. Carpenter GL, Stacks AM. Developmental effects of exposure to intimate partner violence in early childhood: a review of the literature. Child Youth Serv Rev 2009;31:831-9.

8. Luecken LJ, Roubinov DS, Tanaka R. Childhood family environment, social competence, and health across the lifespan. J Soc Pers Relationships 2013;30:171-8.

9. Perkins S, Graham-Bermann S. Violence exposure and the development of school-related functioning: mental health, neurocognition, and learning. Aggress Violent Behav 2012;17:89-98.

10. Pechtel P, Pizzagalli DA. Effects of early life stress on cognitive and affective function: an integrated review of human literature. Psychopharmacology 2011;214:55-70.

11. Holt S, Buckley H, Whelan S. The impact of exposure to domestic violence on children and young people: a review of the literature. Child Abuse Negl 2008;32:797-810.

12. Kim J, Cicchetti D. Longitudinal pathways linking child maltreatment, emotion regulation, peer relations, and psychopathology. J Child Psychol Psychiatry 2010;51:706-16.

13. Enoch MA. The role of early life stress as a predictor for alcohol and drug dependence. Psychopharmacology 2011;214:17-31.

14. Afifi TO, Mather A, Boman J, et al. Childhood adversity and personality disorders: results from a nationally representative population-based study. J Psychiatr Res 2011;45:814-22.

15. Pitzer LM, Fingerman KL. Psychosocial resources and associations between childhood physical abuse and adult well-being. J Gerontol B Psychol Sci Soc Sci 2010;65:425-33.

16. Shaw BA, Krause N. Exposure to physical violence during childhood, aging, and health. J Aging Health 2002;14:467-94.

17. Beaumont J. Measuring national well-being: a discussion paper on domains and measures. Newport: Office for National Statistics, 2011.

18. OECD. OECD guidelines on measuring subjective well-being. European Union: OECD Publishing, 2013.

19. World Health Organization. World report on disability. Geneva: World Health Organization, 2011.

20. Office for National Statistics. First annual ONS experimental subjective well-being results. Newport: Office for National Statistics, 2012.

21. Godefroy P. Life-satisfaction: French people give themselves an average score of 7 out of 10. France, portrait social. Paris: National Institute of Statistics and Economic Studies, 2011.

22. Ura K, Alkire S, Zangmo T, et al. An extensive analysis of the GNH Index. Thimpu: The Centre for Bhutan Studies, 2012.

23. HM Government. No health without mental health. London: Department of Health, 2011.

24. Mental Health Commission of Canada. Changing directions, changing lives: the mental health strategy for Canada. Calgary: Mental Health Commission of Canada, 2012.

25. European Union. European pact for mental health and well-being. European Union: Brussels, 2008.

26. Bellis MA, Lowey $\mathrm{H}$, Hughes $\mathrm{K}$, et al. Variations in risk and protective factors for life satisfaction and mental wellbeing with deprivation: a cross-sectional study. BMC Public Health 2012;12:492.

27. Stewart-Brown S, Tennant A, Tennant R, et al. Internal construct validity of the Warwick-Edinburgh Mental Well-being Scale (WEMWBS): a Rasch analysis using data from the Scottish Health Education Population Survey. Health Qual Life Outcomes 2009;7:15.

28. Waldron S. Measuring subjective wellbeing in the UK. Newport: Office for National Statistics, 2010.

29. Office for National Statistics. Population estimates for England and Wales, mid-2011 (2011 Census-based). http://www.ons.gov.uk/ons/ publications/re-reference-tables.html?edition=tcm\%3A77-262039 (accessed Jun 2013).

30. Bates A. Methodology used for producing ONS's small area population estimates. Popul Trends 2006;125:30-6.

31. Department for Communities and Local Government. English indices of deprivation 2010. London: Department for Communities and Local Government, 2011.

32. Pudney S. An experimental analysis of the impact of survey design on measures and models of subjective wellbeing. Colchester: University of Essex, 2010

33. Office for National Statistics. 2001 Census. http://www.ons.gov.uk ons/guide-method/census/census-2001/about-census-2001/ census-2001-forms/index.html (accessed Jun 2013).

34. Georgellis Y, Tsitsianis N, Yin YP. Personal values as mitigating factors in the link between income and life satisfaction: evidence from the European Social Survey. Soc Indic Res 2009;91:329-44. 
35. Reeskens T, Hooghe M. Cross-cultural measurement equivalence of generalized trust. Evidence from the European Social Survey (2002 and 2004). Soc Indic Res 2008;85:515-32.

36. Batcho KI, Nave AM, DaRin ML. A retrospective survey of childhood experiences. J Happiness Stud 2011;12:531-45.

37. McKee-Ryan F, Song Z, Wanberg CR, et al. Psychological and physical well-being during unemployment: a meta-analytic study. $J$ Appl Psychol 2005;90:53-76.

38. Aked J, Thompson S. Five ways to wellbeing: new applications, new ways of thinking. London: NHS Confederation, New Economics Foundation, 2011

39. Jose PE, Ryan N, Pryor J. Does social connectedness promote a greater sense of well-being in adolescence over time? J Res Adolesc 2012;22:235-51.

40. Wang $\mathrm{H}$, Schlesinger $\mathrm{M}$, Wang $\mathrm{H}$, et al. The flip-side of social capital: the distinct influences of trust and mistrust on health in rural China. Soc Sci Med 2009;68:133-42.

41. Poortinga W. Social capital: an individual or collective resource for health? Soc Sci Med 2006;62:292-302.

42. UNICEF. Thematic report 2010: child protection from violence, exploitation and abuse. New York: UNICEF, 2010.

43. Council of Europe. Council of Europe strategy on the rights of the child (2012-2015). http://www.coe.int/t/dg3/children/ (accessed Jun 2013)

44. Dube SR, Williamson DF, Thompson T, et al. Assessing the reliability of retrospective reports of adverse childhood experiences among adult $\mathrm{HMO}$ members attending a primary care clinic. Child Abuse Negl 2004;28:729-37.

45. Hardt J, Rutter M. Validity of adult retrospective reports of adverse childhood experiences: review of the evidence. J Child Psychol Psychiatry 2004;45:260-73.
46. Anda RF, Butchart A, Felitti VJ, et al. Building a framework for global surveillance of the public health implications of adverse childhood experiences. Am J Prev Med 2010;39:93-8.

47. MacCallum RC, Zhang S, Preacher KJ, et al. On the practice of dichotomization of quantitative variables. Psychol Methods 2002; 7:19-40.

48. Gilbert R, Kemp A, Thoburn J, et al. Recognising and responding to child maltreatment. Lancet 2009;373:167-80.

49. Olds DL, Eckenrode J, Henderson CR Jr, et al. Long-term effects of home visitation on maternal life course and child abuse and neglect. Fifteen-year follow-up of a randomized trial. JAMA 1997; 278:637-43.

50. Fergusson DM, Grant $\mathrm{H}$, Horwood J, et al. Randomized trial of the early start program of home visitation. Pediatrics 2005;116:e803-9.

51. Prinz RJ, Sanders MR, Shapiro CJ, et al. Population-based prevention of child maltreatment: the U.S. Triple P System population trial. Prev Sci 2009;10:1-12.

52. Reynolds AJ, Robertson DL. School-based early intervention and later child maltreatment in the Chicago Longitudinal Study. Child Dev 2003;74:3-26.

53. Reynolds AJ, Ou SR, Topitzes JW. Paths of effects of early childhood intervention on educational attainment and delinquency: a confirmatory analysis of the Chicago Child-Parent Centers. Child Dev 2004;75:1299-328.

54. Eckenrode J, Campa M, Luckey DW, et al. Long-term effects of prenatal and infancy nurse home visitation on the life course of youths: 19-year follow-up of a randomized trial. Arch Pediatr Adolesc Med 2010;164:9-15.

55. Bellani L, D'Ambrosio C. Deprivation, social exclusion and subjective well-being. Soc Indic Res 2011;104:67-86. 